\title{
Learning English Language and Communication Skills Online during COVID 19 Pandemic: Opportunities and Challenges
}

\author{
Preeti Oza \\ St. Andrew's College, University of Mumbai, Mumbai, Maharashtra, India \\ Email: preetioza1@gmail.com
}

How to cite this paper: Oza, P. (2022). Learning English Language and Communication Skills Online during COVID 19 Pandemic: Opportunities and Challenges. Open Journal of Social Sciences, 10, 442-450. https://doi.org/10.4236/jss.2022.102031

Received: January 4, 2022

Accepted: February 25, 2022

Published: February 28, 2022

Copyright ( 2022 by author(s) and Scientific Research Publishing Inc. This work is licensed under the Creative Commons Attribution International License (CC BY 4.0).

http://creativecommons.org/licenses/by/4.0/

\begin{abstract}
The goal of this study was to look at the opportunities and challenges of learning the English language and communication skills online during the COVID 19 pandemic. To meet the aims, the researcher created a comprehensive questionnaire containing information on many aspects of teaching Communication Skills in English. The information was gathered from the respondents using e-forms and personal interactions, as well as the designed scale. After gathering data, tables were created to classify the information, and regression was used to analyze the information. The study also discusses the abilities and competencies that teachers must possess to effectively teach English in online learning contexts. These abilities and talents are divided into six groups: educational skills, subject skills, design skills, technical skills, managerial and institutional skills, and social and communication skills.
\end{abstract}

\section{Keywords}

Learning Online English Language, Learning Online Communication Skills, Online during COVID 19 Pandemic

\section{Introduction}

\subsection{A Glance at Online Learning}

Online Learning Terminologies and Definitions: Since the rise of online learning, a plethora of terminologies and definitions have been employed to define it. E-learning, virtual learning, cyberlearning, Internet learning, distributed learning, web-aided learning, web-based learning, remote learning, computer-based learning, resource-based learning, and technology-based learning are some of the names widely used to characterize online learning. Throughout this work, 
the term "online learning" will be utilized. Because of the wide range of terminologies used, there are many alternative definitions of online learning. Online learning has been defined in a variety of ways by authors, researchers, theorists, and educators from a variety of views and fields. Some people define online learning as learning that takes place wholly online (pure online learning) or partially online (blended learning). Others refer to online learning as "internet-based instructional settings." By providing access to learning materials via the Internet, interacting with the content, instructor, and other learners, and receiving support during the learning process, online learning as a learning experience allows for personal growth, knowledge acquisition, and the construction of personal meaning. In addition, new online learning forms, such as mobile learning and MOOCs, have arisen. "Learning that takes place in learning environments and spaces that take into account the mobility of technology, the mobility of learners, and the mobility of learning" is defined as "learning that takes place in learning environments and spaces that take into account the mobility of technology, the mobility of learners, and the mobility of learning." MOOCs (Massive Open Online Courses) are a hybrid of online learning and open educational materials. MOOCs are online courses that are free, open, and non-credit. They are offered by several higher education institutions.

\subsection{Research Background}

Despite the fact that several studies have looked into the challenges of COVID-19's remote English education, one key research gap that has yet to be filled is evaluating the relevant pedagogic experiences and suggestions provided on language teacher educators' blogs. This study looked at fifty-one blogs authored by teacher educators and posted on four well-known language education websites to see how they felt about COVID-19-related online English language instruction difficulties and potential solutions. COVID-19 has wreaked havoc on the majority of the world's industries. In most places around the world, education is the only industry that has entirely transitioned to an online method. During the epidemic, online learning was the best option for continuing education, especially in tertiary education.

The goal of this research is to find out what hurdles and obstacles English language learners face (EFL). In order to overcome these challenges, many teacher educators suggested coping strategies such as planning for online teaching, managing online classrooms, supporting students' mental health, enhancing students' ability to use/access technology, fostering active language learning engagement and motivation, and promoting teacher professional practices and wellbeing.

\subsection{Problem Statement and Proposed Solutions}

There are some recurrent issues across the higher education but this paper deals with a specific topic of teaching English language online in a big classroom of a college. 


\section{Review of Literature}

Online learning is defined as learning that takes place over the internet and is aided by electronic devices such as tablets, smartphones, laptops, and PCs (González, 2018). Because of the widespread usage of online learning, students are naturally drawn to other online language learning options (Plaisance, 2018). A set of learning activities in a subject offered over a network providing access and knowledge exchange is referred to as online learning. This phrase was coined to describe a method of teaching and learning that incorporates the use of internet technologies. Students can use the online learning environment to not only access information and materials, but also to connect and collaborate with other students in the course (Krish, 2008). Students and teachers are more comfortable with online learning and perceive the opportunity of setting up and accessing opportunities to study in a different way. Online language learning (OLL) can refer to a variety of learning styles, including web-based learning, hybrid or blended learning, and virtual or online learning. Furthermore, because students and teachers are unable to meet in a face-to-face setting during the COVID-19 pandemic, online language learning in an EFL context in secondary school settings takes place entirely online (Blake, 2011). In the year 2002, an average of 1700 institutions offered over 54,000 online courses. But gradually there has been a steady rise in such courses worldwide, and almost all the universities all over the world have started offering such courses. The idea of MOOC has been a hit in the area of online teaching-learning and in India also the government has started promoting virtual online courses through various platforms like NPTEL, PG Pathshlala, Swayam, and many more. Ambani-Birla Report in 2000 recommended the entire removal of the subsidized system and converting higher education into a fully controlled profitable market. Under the influence of the Ambani-Birla Report, UGC recommended the restructuring of higher education in the market-oriented enterprises promoting corporate values. Under neoliberal agendas, India has agreed to consider education a tradable service (Oza, 2021). Online learning may also be defined as the use of the internet to access materials, engage with content, teachers, and other students, and receive aid in the learning process to gain information, make meaning, and progress through the learning process (Ally, 2008).

\section{Analysis of Data}

Total 400 students of various UG colleges in Mumbai region were approached for this data collection. All the respondents have studies Communication Skills and English language during lockdown in online mode. The data was collected in a pre-structured questionnaire given to the samples. The data is collected from the classes where students have opted for Social sciences or Humanities courses.

Figure 1 shows that most of the respondents (more than 78 percent) are girls. This is due to the higher ratio of girls taking Social Science and Humanities 
courses.

As shown in Figure 2, most of the respondents are undergraduate students or junior college students (class 11 and 12). So English Language teaching is a part of the prescribed curriculum for them. In most of the universities in India, it is a part of the Foundation course and a part of the non-core papers. So learning the English language as a part of the communication skill-building exercise is not a core part of the curriculum.

As shown in Figure 3, almost all the participants have studied the English language as a part of the structured curriculum. Most of the UG programs have either Communication Skills or Business Communication as a part of the capacity-building foundation courses and they are compulsory for the first two semesters.

As explained in Figure 4 not many respondents are able to take any stand on this question. Almost half of the total respondents are neutral and more than 27 percent of total respondents are either not agreeing or completely disagree.

Figure 5 provides some comprehensive understanding on Some of the regular components of the curriculum are comprehension skills, editing and summary writing, basic grammar and vocabulary exercises, letter writing, biodata and resume writing, important theories of communication, verbal and non-verbal

\section{gender}

193 responses

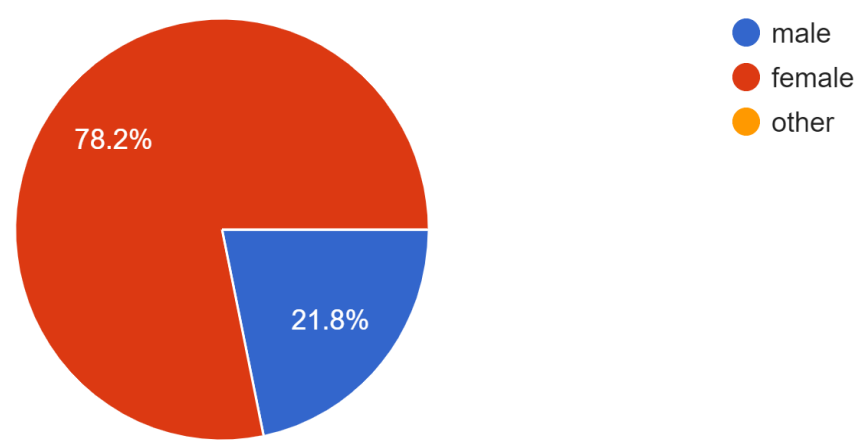

Figure 1. Demographic of respondents-UG colleges in Mumbai region.

You were in the class during 2020-21

193 responses

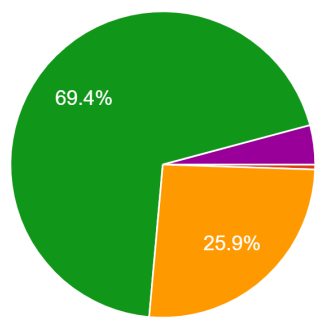

school - class 4-7

school - class 8-10

junior college- class 11-12

degree college - First / second/third year of college

PG

Figure 2. Academic positioning of respondents-UG colleges in Mumbai region. 
You have studies English / Communication Skills / Business Communication as a subject in the last academic year

193 responses
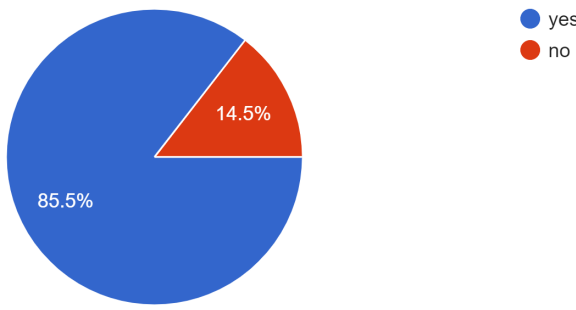

Figure 3. data showing students' eligibility for the data on the subjects like English and Communication skills-UG colleges in Mumbai region.

you think that the online mode is better for studying English Communication Skills 193 responses
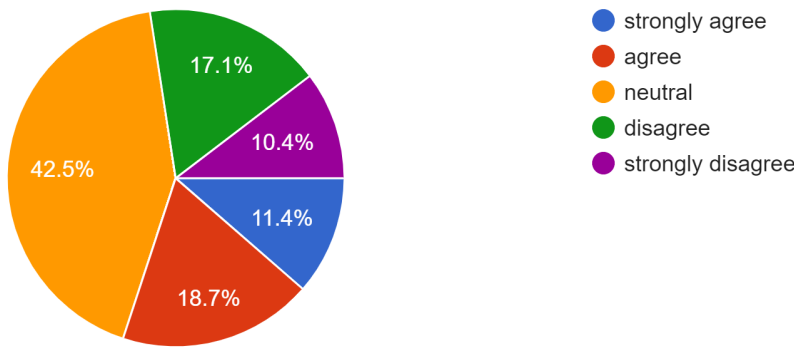

Figure 4. Preferences for the mode of teaching-learning-UG colleges in Mumbai region.

Which areas of English Communication studies you think CAN BE TAUGHT online effectively? (you may select multiple options also)

193 responses

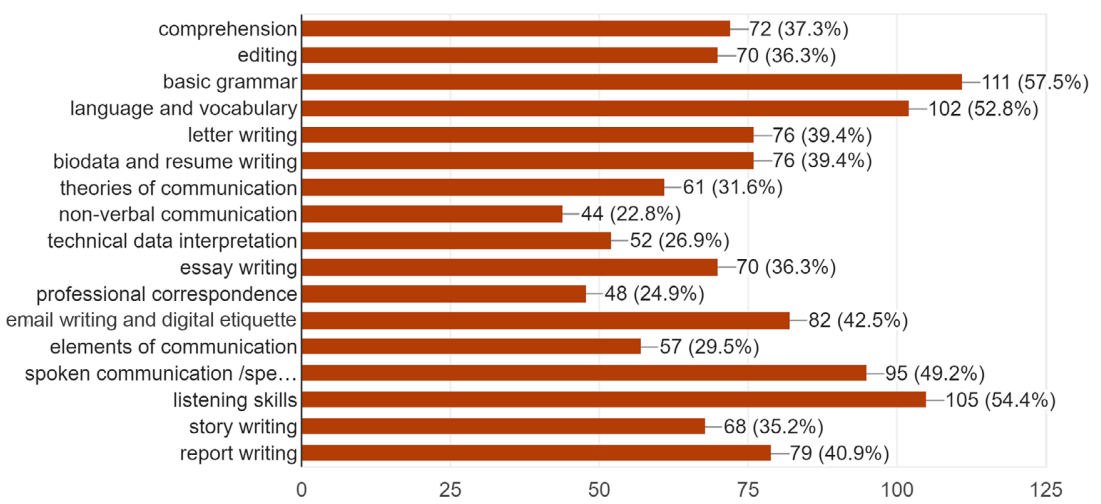

Figure 5. Multiple choices of respondents about specific areas of English language teaching-UG Colleges in Mumbai region.

communication, technical data interpretation, essay writing, professional correspondence, email writing and digital etiquette, elements of communication, spoken communication, listening skills, story writing or report writing.

Participants are the most comfortable with the basic grammar, vocabulary and listening skills in online mode. At the same time, non-verbal communication 
and professional correspondence are the most difficult for them to study online.

Figure 6 is a cumulative data where respondents have marked the problem areas and the challenges faced by them during online teaching for English language and Communication skills. Non-vernal Communicating and Professional Correspondence are the most dreaded topic for the students to learn online. Even report writing and technical data interpretation are marked as challenges by more than half of the respondents.

Figure 7 provides an in-depth analysis on teachers' choice of mode of ICT. Most of the teachers are using the following tools to teach Language and Communication Skills online: Powerpoint presentations, PDF notes, flipped classrooms, videos, live conversations, written assignments, group discussions, quiz and interactive discussions. As per the data receives, PPTs and PDF notes are the most popular amongst teachers.

This is a very clear response as we can see in Figure 8, that the majority of students prefer offline mode to learn Communication skills and the English language.

Which areas of English Communication studies you think SHOULD NEVER BE TAUGHT online ?(you may select multiple options also)

193 responses

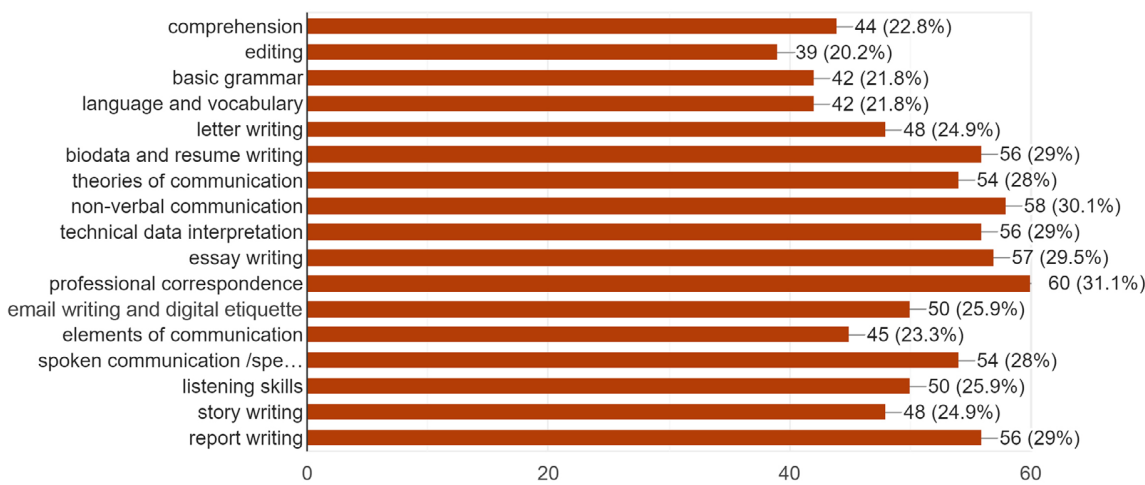

Figure 6. The problem areas identified by respondents for English language teaching online-UG colleges in Mumbai region.

What are some of the major online tools used by your teacher in the English Communication Skills class?

193 responses

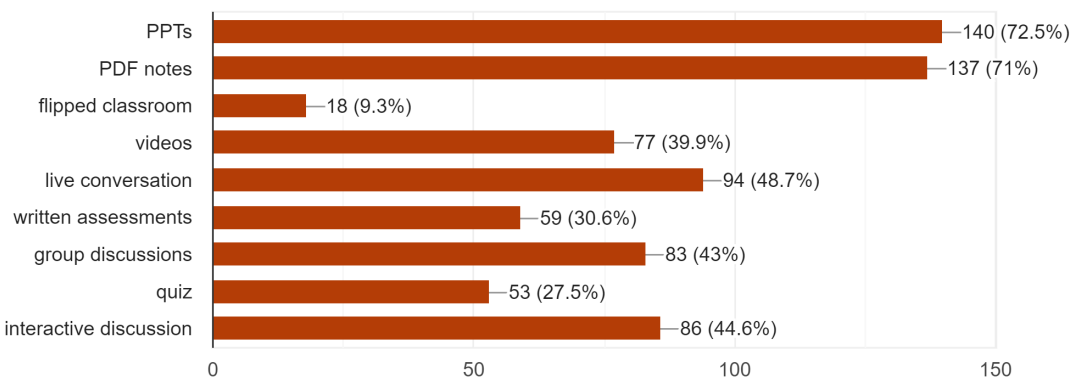

Figure 7. Selection of major online tools by teachers in the class-UG colleges in Mumbai region. 
As per Figure 9, when it's about the interaction in the classroom, not many students are responding positively to the online mode of learning.

Figure 10 gives us the evidence that the perception amongst students about the teacher's digital competence also is questionable here. When approx. 55 percent of students accept that their teachers can handle digital tools, the others do not think so or have their doubts.

Which mode of teaching you would like for the subject of English Communication Skills? 193 responses

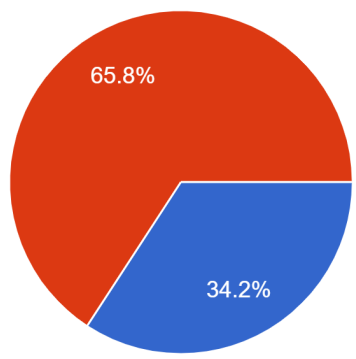

Figure 8. Preference of the mode to study English communication-UG colleges in Mumbai region.

you like to take active participation in the class of English Communication Skills 193 responses

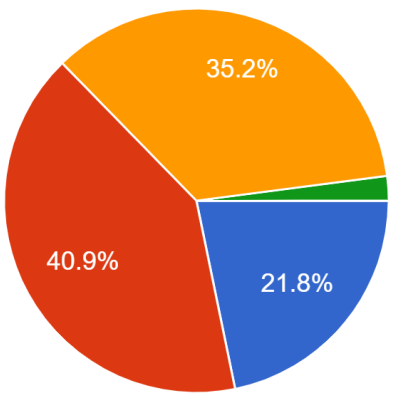

strongly agree

agree

neutral

disagree

strongly disagree

Figure 9. Students' participation in the class of communication skills-UG colleges in Mumbai Region.

you think that your teacher is competent in digital tools for teaching English communication Skills 193 responses
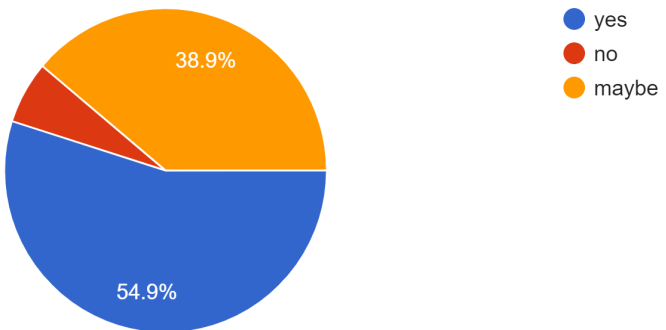

Figure 10. Opinion on the teacher's competence with digital tools-UG Colleges in Mumbai Region. 
what would you prefer as a evaluation / exam in the subject of English/ Communication skills? ( you may select multiple options)

193 responses

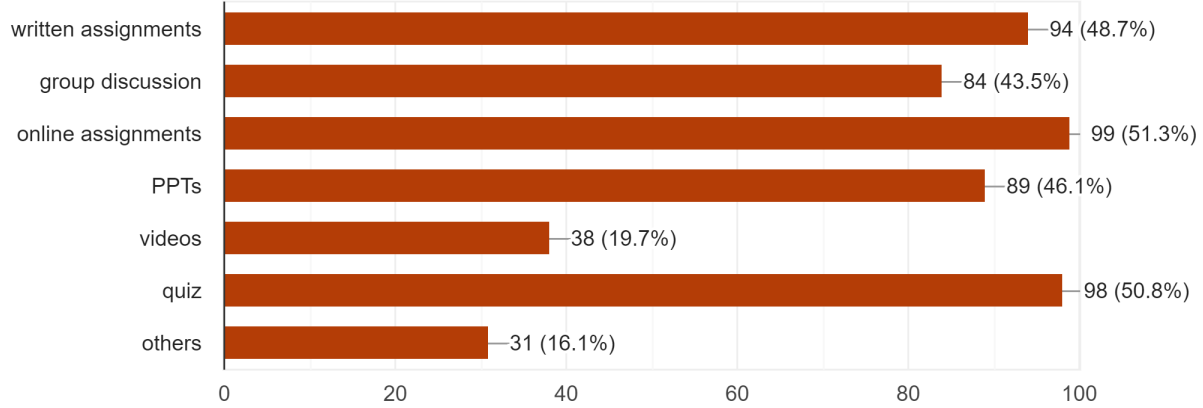

Figure 11. Nature of evaluation and examination for English communication online-UG colleges in Mumbai region.

you think that online recorded videos can replace the presence of a teacher in a Communication Skills class.

193 responses
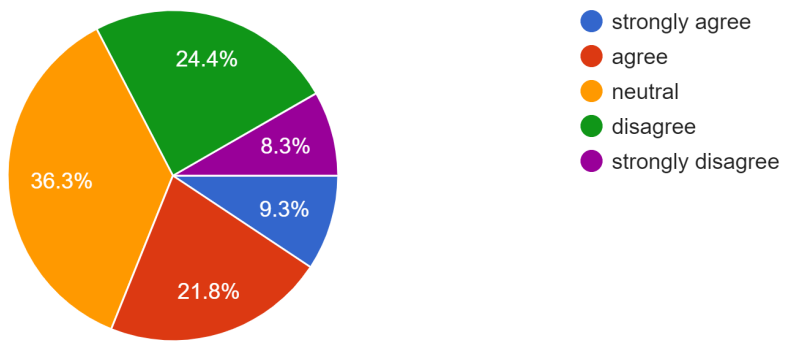

Figure 12. Opinion on the position of a teacher as compared to the online content and study Material-UG Colleges in Mumbai Region.

Figure 11 analyses the evaluation process in the online mode. The evaluation and assessment in the subject of English language and communication skills is a complex process and needs to follow up as a part of the language acquisition process also unlike any other academic subject. Most learners prefer to get an assignment of a group discussion for examination.

Figure 12 gives us a data on the importance of teacher. This perception-based data also speaks a lot about the state of online teaching of the subjects like Communication Skills in English. More than 60 percent of respondents agree that the online video can replace the presence of a teacher in an online communication skills classroom.

\section{Conclusion and Some Suggestions for the Teachers}

Teaching English online, in contrast to face-to-face classes, comes with its own set of challenges. Although the fundamentals of online classes are similar to those of traditional classes, some professors may find the transition difficult. Here are some of the most common challenges that new online English teachers experience, as well as how to overcome them. When it comes to online English 
teachers, the most difficult obstacle and source of anxiety are experiencing troubles with their Internet connection or computer or laptop. Because they are still getting used to the platform and teaching in an online context, this is a big problem for first-time online teachers. Some suggestions for a teacher are: To avoid technical problems, make sure that all of your computer equipment fulfills the minimum requirements and that you've researched how to use the platform; check your computer equipment for any defects that need to be fixed before each lesson; get a backup power and Internet source to avoid missing a lesson if there is a power outage. First-time teachers of English may miss the fact that they are communicating to students who have little or no prior knowledge of the English language. As a result, they inadvertently use concepts that appear easy but are difficult for youngsters to understand. In the classroom, the expression "Let's go to the next page" or "Let's go on to the next page" is commonly used. Many pupils, especially beginners or children, will struggle to comprehend these words. It is advisable to use simple language like "Let's go to the next page" instead of direct command. If you utilize simple language, your children will comprehend you better, activate your students' interest and attention in the classroom. Keeping students engaged, whether in the classroom or online, is a common difficulty for online educators. As a result, students in an online classroom are more likely to be distracted than those in a traditional classroom. Furthermore, English teachers who teach online sometimes find it difficult to stay focused because they have no control over their environment. It is advisable to make an effort to include children as much as possible to keep them involved and focused, additionally, make the lessons more entertaining to pique students' interest.

\section{Conflicts of Interest}

The author declares no conflicts of interest regarding the publication of this paper.

\section{References}

Ally, M. (2008). The Impact of Technology on Education. In Education for a Digital World: Advice, Guidelines and Effective Practice from Around the Globe (pp. 57-66).

Blake, R. J. (2011). Current Trends in Online Language Learning. Annual Review of Applied Linguistics, 31, 19-35. https://doi.org/10.1017/S026719051100002X

González, A. (2018). Turning a Traditional Teaching Setting into a Feedback-Rich Environment. International Journal of Educational Technology in Higher Education, 15, Article Number: 32. https://doi.org/10.1186/s41239-018-0114-1

Krish, P. (2008). Language Learning in the Virtual World: Instructors' Voices. International Journal of Pedagogies and Learning, 4, 113-129. https://doi.org/10.5172/ijpl.4.4.113

Oza, P. (2021). Policy Shift from Pedagogy to Andragogy in Online Distance Learning: Is Heutagogy an Answer? https://doi.org/10.2139/ssrn.3842914

Plaisance, M. (2018). Online Course Delivery. In The TESOL Encyclopedia of English Language Teaching (pp. 1-6). https://doi.org/10.1002/9781118784235.eelt0129 